\title{
Journal of Parenteral and Enteral Nutrition \\ http://pen.sagepub.com/
}

Whey- vs Casein-Based Enteral Formula and Gastrointestinal Function in Children With Cerebral Palsy

Karina Savage, Stamatiki Kritas, Andrea Schwarzer, Geoffrey Davidson and Taher Omari

JPEN J Parenter Enteral Nutr 2012 36: 118 S

DOI: $10.1177 / 0148607111428139$

The online version of this article can be found at:

http://pen.sagepub.com/content/36/1_suppl/118S

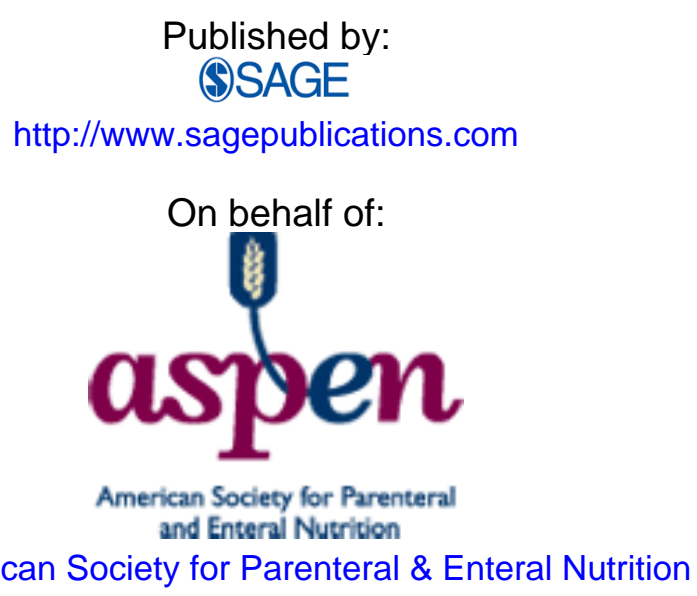

Additional services and information for Journal of Parenteral and Enteral Nutrition can be found at:

Email Alerts: http://pen.sagepub.com/cgi/alerts

Subscriptions: http://pen.sagepub.com/subscriptions

Reprints: http://www.sagepub.com/journalsReprints.nav

Permissions: http://www.sagepub.com/journalsPermissions.nav

>> Version of Record - Jan 11, 2012

What is This? 


\author{
Karina Savage, BND, BSc ${ }^{1,2}$; Stamatiki Kritas, BSc (Hons) ${ }^{1}$; \\ Andrea Schwarzer, $\mathrm{MD}^{3}$; Geoffrey Davidson, MBBS, MD, \\ FRACP $^{1}$; and Taher Omari, MBBS, PhD, FRACP ${ }^{1}$
}

Financial disclosure: Funded by The Financial Markets Foundation for Children, Australia. The whey (trial) formulas were donated by Nestlé Clinical Nutrition, Vevey, Switzerland. The publication of the supplement in which this article appears is sponsored by Nestlé Nutrition Institute.

Objectives: Children with severe cerebral palsy (CP) commonly have gastrointestinal (GI) dysfunction. Whey-based enteral formulas have been postulated to reduce gastroesophageal reflux (GOR) and accelerate gastric emptying (GE). The authors investigated whether whey-based (vs casein-based) enteral formulas reduce GOR and accelerate GE in children who have severe CP with a gastrostomy and fundoplication. Methods: Thirteen children received a casein-based formula for 1 week and either a $50 \%$ whey whole protein $(50 \% \mathrm{WWP})$ or a $100 \%$ whey partially hydrolyzed protein (100\% WPHP) formula for 1 week. Reflux episodes, gastric half-emptying time (GE $\mathrm{t}_{1 / 2}$ ), and reported pain and GI symptoms were measured. Results: Whey formulas emptied significantly faster than casein (median [interquartile range (IQR)] GE $\mathrm{t}_{1 / 2}, 33.9$ [25.3-166.2] min vs 56.6 [46-191] min; $P=.033)$. Reflux parameters were unchanged. GI symptoms were lower in children who received 50\% WWP (visual analog symptom score, median [IQR], 0 $[0-11.8])$ vs $100 \%$ WPHP $(13.0$ [2.5-24.8]) $(P=.035)$. Conclusion: This pilot study shows that in children who have severe CP with a gastrostomy and fundoplication, GE of the whey-based enteral formula is significantly faster than casein. The acceleration in GE does not alter GOR frequency, and there appears to be no effect of whey vs casein in reducing acid, nonacid, and total reflux episodes. The results indicate that enteral formula selection may be particularly important for children with severe CP and delayed GE. (JPEN J Parenter Enteral Nutr. 2012;36:118S-123S)

Keywords: pediatrics; life cycle; enteral formulas; enteral nutrition; gastroenterology; proteins

\section{Clinical Relevancy Statement}

Our study showed that children who have severe cerebral palsy $(\mathrm{CP})$, with a gastrostomy and fundoplication, had significantly faster gastric emptying (GE) with wheybased enteral formulas (either $50 \%$ whey or $100 \%$ whey) compared to a casein-based formula. Five of the 13 children $(39 \%)$ who had delayed GE with the casein formula, normalized with one of the whey-based formulas (using

From the ${ }^{1}$ Department of Gastroenterology; ${ }^{2}$ Department of Nutrition, Women's and Children's Hospital, Women's \& Children's Health Service, North Adelaide, South Australia; and ${ }^{3}$ Dr Von Haunersches Kinderspital, Ludwig Maximilians University, Munich, Germany

Received for publication October 4, 2011 ; accepted for publication October 4, 2011.

Address correspondence to: Karina Savage, Department of Gastroenterology, Women's \& Children's Hospital, Women's \& Children's Health Service, 72 King William St, North Adelaide, 5006, South Australia; e-mail: karina.savage@health.sa.gov.au. the age-related reference range). Standard practice for enteral feeding has historically involved the use of caseinbased enteral formulas. In the scenario of a child with CP and delayed GE, a trial of a whey-based enteral formula may be warranted.

\section{Introduction}

Children with severe cerebral palsy (CP) commonly suffer gastrointestinal (GI) dysfunction ${ }^{1,2}$ related to malfunction of their enteric nervous system (ENS). ${ }^{3}$ Malfunctions of their ENS can lead to conditions such as gastroesophageal reflux (GOR), delayed gastric emptying (GE), and gastric dysrhythmias. ${ }^{4}$ GI dysfunction can contribute to symptoms of abdominal pain, diarrhea, regurgitation, vomiting, and constipation, ${ }^{5,6}$ which are often complications of enteral feeding in this population. Furthermore, GI symptoms in a child with severe $\mathrm{CP}$ do not always receive appropriate medical attention because of the child's inability to verbally communicate discomfort. $^{7}$ 
The incidence of GOR is higher in children with CP compared with the general population, ${ }^{4,6,8,9}$ and delayed $\mathrm{GE}$ is also common, ${ }^{2,10}$ with reports that $67 \%$ of children with $\mathrm{CP}$ and GOR have significantly delayed GE. ${ }^{5}$ Clinical manifestations include early satiety, nausea, vomiting, and retching, as well as an increased risk of aspiration. ${ }^{2}$

The few studies published in the area suggest that specific modification of the protein in the enteral formula may be a useful adjunct in the management of GI dysfunction in children with severe CP. ${ }^{11-14}$ Whey-based formulas (compared to casein) have been postulated to reduce $\mathrm{GOR}^{14}$ and accelerate GE. ${ }^{12,13}$ The purported benefits of whey protein relate to the predominance of $\beta$-lactoglobulin, which remains soluble in the stomach, therefore transiting more rapidly to the upper jejunum. Casein protein, in contrast, clots and or precipitates in the acid environment of the stomach, resulting in slower GE. ${ }^{15}$

The aim of this study was primarily to determine whether whey-based (vs casein-based) enteral formulas reduce GOR and accelerate GE in enterally fed children with severe CP. Second, we aimed to examine the effect of these formulas on symptoms of poor feed tolerance such as gagging, regurgitation, irritability, pain, and constipation.

\section{Methods}

\section{Study Population}

Thirteen children ( 8 male, 5 female; mean age 7.2 years [range, 2.4-15.4 years]) with severe CP were enrolled. Eleven were of Caucasian background, 1 was of Asian descent, and 1 was of Aboriginal descent. Type of CP included 7 with spastic quadriplegia, 3 with spastic diplegia, 2 with hypotonia, and 1 with dyskinetic CP. All were $100 \%$ enterally fed-12 via percutaneous endoscopic gastrostomy (PEG) tube and 1 via a nasogastric tube (NGT). All children except for the child receiving NGT feeds had undergone at least 1 fundoplication procedure $(2$ children had undergone 2). They were fed via daytime boluses with or without overnight continuous feeds via a pump. Their feeding regime during the study was either identical or as close as possible to their usual regimethis included factors such as frequency of feeds, total volume, and caloric/nutrient composition. All children were assessed by a pediatric dietitian as "nutritionally sound," with their height appropriate for their weight percentile using Centers for Disease Control and Prevention (CDC) percentile charts. Height was measured using Knee Height Callipers (Ross Laboratories, Columbus, Ohio) and converted using the validated equation into height. ${ }^{16}$ Weight was measured either using standing scales (parent/caregiver holding child) or using wheelchair scales.
Children were recruited from the Women's and Children's Hospital Home Enteral Nutrition Database. Ethical approval was obtained from the Human Research Ethics Committee CYHWS (REC1997/9/10). All patients complied with the following inclusion criteria: (1) CP with severe neurological impairment graded by the Cerebral Palsy Gross Motor Function Classification Scale (levels 4-5), (2) history of GOR, (3) 100\% dependent on enteral nutrition (to prevent oral consumption of food proteins that may potentially confound results), (4) well matched for height/weight (to avoid any confounding affect of improved nutrition on GI function), ${ }^{17}$ (5) no concurrent use of antibiotics (due to their potential affect on GE), and (6) no GI surgery in past 3 months (as delayed GE may occur after surgical placement of a PEG tube). ${ }^{18}$

\section{Medications}

Because patients acted as their own controls, they all continued their usual medication regime throughout the entire study. Five patients were taking baclofen (Alphapharm Pty Ltd, Glebe NSW, Australia, and Apotex Pty Ltd, North Ryde, NSW, Australia), and 3 were taking omeprazole (AstraZeneca, North Ryde NSW, Australia).

\section{Study Design and Investigations}

This pilot study was a randomized, double-blind, crossover clinical trial in which children received a standard casein-based enteral formula (Pediasure [82\% casein, 18\% whey]; Abbott Australasia, NSW, Australia) for 1 week and either a 50\% whey, 50\% casein whole-protein (50\% WWP) formula (Nutren Junior; Nestle Clinical Nutrition, Vevey, Switzerland) for 1 week $(\mathrm{n}=7)$ or a $100 \%$ whey partially hydrolyzed protein (100\% WPHP) formula (Peptamen Junior; Nestle Clinical Nutrition) for 1 week $(n=6)$. Order of casein vs whey formula was also randomized. Each patient served as his or her own control for paired comparison. There was no washout between different formulas as patients were given each formula for 6-7 days prior to testing.

\section{Multichannel Intraluminal Impedance With pH-metry}

On days 6-7 of each week, a multichannel intraluminal impedance (MII) ambulatory data logger (Sleuth; Sandhill Scientific, Littleton, CO) was used to perform esophageal pH-MII monitoring studies (acid and nonacid reflux). A ComforTech Infant catheter (Sandhill Scientific, Denver, $\mathrm{CO})$, with 6 impedance segments (1.5-cm spacing) and a $\mathrm{pH}$ sensor located at the distal segment, was used. After calibration and intubation, correct position (between T6 and T8) of the $\mathrm{pH}$ sensor was confirmed by a lateral chest $\mathrm{X}$-ray. Parents/guardians were instructed to maintain normal 
daily routines. The catheter remained in situ for a minimum of 20 hours and a maximum of 24 hours. Children continued their normal enteral feed regime during this time. At the completion of the study, the information recorded on the data logger was downloaded and the tracings were manually analyzed using semi-automated impedance analysis software (Bioview; Sandhill Scientific) to determine the occurrence of acid and nonacid reflux. Liquid GOR episodes were identified by a decrease in impedance of at least $50 \%$ from baseline traveling retrograde in the esophageal body. The proximal extent of reflux was defined by the most proximal impedance channel demonstrating an impedance drop of $>50 \%$ from baseline. For each impedance-detected GOR episode, the $\mathrm{pH}$ of the refluxate was determined by the esophageal $\mathrm{pH}$ sensor. Reflux episodes were defined according to esophageal $\mathrm{pH}$ as acidic $(\mathrm{pH}<4)$ or nonacidic $(\mathrm{pH} \geq 7)$. Acid reflux index (\% time $\mathrm{pH}<4$ ) was determined using automated analysis of the $\mathrm{pH}$ tracing (GERD Check; Sandhill Scientific).

\section{Gastric Emptying}

On day 6 of each week, GE rate was measured using the ${ }^{13} \mathrm{C}$-Na-octanoate breath test using ${ }^{13} \mathrm{C}$-labeled $\mathrm{Na}$-octanoate (50 mg, 99\% enrichment; Cambridge Isotope Laboratories, Andover, MA). Patients were fasted overnight and then given a 200-mL bolus of either the casein or whey formula containing $100 \mathrm{mg}{ }^{13} \mathrm{C}$-Na-octanoate for breath test measurement of liquid GE. Breath samples were taken using a small flexible tube connected to a syringe, which was held in close proximity to the patient's mouth or nose as he or she breathed out. Samples were taken before the bolus and afterward at 5-minute intervals until 30 minutes and 15-minute intervals until 4 hours. Patients remained recumbent in their wheelchair, in a pram, or on a hospital bed for the 4-hour study period. Breath samples were analyzed for ${ }^{13} \mathrm{CO}_{2}$ content using an isotope ratio mass spectrometer (IRMS; Europa Scientific, ABCA 20/20, Crewe, UK), and the ${ }^{13} \mathrm{CO}_{2}$ excretion rate curves were used to calculate the gastric half-emptying time $\left(\mathrm{GE} \mathrm{t}_{1 / 2}\right)$ using an established nonlinear regression model. ${ }^{19}$ Age-related reference ranges ${ }^{20}$ for liquid GE $\mathrm{t}_{1 / 2}$ were then used to compare GE with various formulas.

\section{Symptoms}

Symptoms were reported by parents throughout the study using 3 methods:

1. Parent recording sheet (completed at home for the 2-week duration of the study)

2. Visual analog scale (VAS) questionnaire for 5 symptoms (gagging, regurgitation, irritability, pain, and constipation). Scoring for each symptom involved placing a mark along a $10-\mathrm{cm}$ line (far left indicating no symptom and far right indicating severe symptom).

\section{A Non-Communicative Children's Pain Checklist $(\mathrm{NCCPC})^{21}$}

The latter 2 were completed by the parent/caregiver when visiting the hospital for testing on day 6 of each week.

\section{Study Formulas}

The casein formula and 2 whey formulas were comparable with respect to calories, protein, carbohydrates, fat concentration, and osmolality (information provided by manufacturer). They were all lactose free with very similar carbohydrate sources. Aside from the protein type and fractionation, the only other difference was the type of fat, with the $100 \%$ WPHP consisting of predominantly medium-chain triglycerides (MCTs) compared to the other 2 formulas (50\% WWP and casein formula), which predominantly contained long-chain triglycerides (LCTs) (Table 1). Parents and staff undertaking investigations and questionnaires were blinded to all formulas.

\section{Statistical Analysis}

All results have been reported as the median value (interquartile range). SigmaStat 11.0 software (SPSS, Inc, an IBM Company, Chicago, IL) was used to perform the statistical analyses. The Wilcoxon signed-ranks test was used to compare significance for the whole group $(n=13$; ie, casein vs whey). The Mann-Whitney rank sum test was used to test for a difference in effect between the 2 different whey-based formulas. A Spearman rank correlation was used to compare GE and reported symptoms/pain.

\section{Results}

Thirteen children were enrolled in the study, and all completed the GE breath tests $(\mathrm{n}=13)$ and symptoms reporting $(\mathrm{n}=13)$. The parent of 1 child declined to complete the impedance-pH study, and 1 impedance-pH study could not be analyzed due to catheter malfunction $(n=11)$.

\section{Reflux}

As a combined group, there was no significant difference between casein and whey formula for total reflux episodes (55 [10-111] vs 29 [16-142]) or reflux pH index (0 [0-1.7] vs $0.7[0-2.6])$, respectively, nor was there a difference between the 2 whey formulas (Table 2).

\section{Gastric Emptying}

Median GE $\mathrm{t}_{1 / 2}$ as a combined group was $40 \%$ faster with a whey formula (33.9 [25.3-166.2] min) compared to the casein formula $(56.6[46-191] \mathrm{min})(P=.033)$. Both of 
Table 1. Nutrition Comparison of the Casein Formula, 50\% Whey Whole Protein Formula, and 100\% Whey Partially Hydrolyzed Formula

\begin{tabular}{|c|c|c|c|}
\hline Formula Analysis per $100 \mathrm{~mL}$ & $\begin{array}{c}\text { Casein Based } \\
(82 \% \text { Casein, } 18 \% \text { Whey })\end{array}$ & $\begin{array}{l}\text { 50\% Whey Whole Protein } \\
(50 \% \text { Whey, 50\% Casein) }\end{array}$ & $\begin{array}{l}100 \% \text { Whey Partially } \\
\text { Hydrolyzed Protein }\end{array}$ \\
\hline Energy, kcal & 100 & 100 & 100 \\
\hline Туре & Whole & Whole & Peptides \\
\hline Source & $82 \%$ casein $18 \%$ whey & $50 \%$ casein $50 \%$ whey & $100 \%$ whey \\
\hline Carbohydrate, $\mathrm{g}$ & 11.0 & 13.3 & 13.8 \\
\hline Fat, $g$ & 5 & 4 & 3.9 \\
\hline $\mathrm{LCT}, \%$ & 80 & 79 & 40 \\
\hline Source & $\begin{array}{l}\text { High oleic sunflower oil, } \\
\text { soya oil }\end{array}$ & $\begin{array}{l}\text { High oleic sunflower oil, low erucic } \\
\text { rapeseed oil, corn oil, soya lethicin }\end{array}$ & $\begin{array}{l}\text { Soya oil, high oleic sunflower } \\
\text { oil, soya lecithin }\end{array}$ \\
\hline MCT, \% & 20 & 21 & 60 \\
\hline
\end{tabular}

LCT, long-chain triglyceride; MCT, medium-chain triglyceride.

Table 2. Median (Interquartile Range) Values for Total Reflux, Acid and Nonacid Episodes, and Reflux Index Over the 24-Hour Period for Casein vs 50\% Whey Whole Protein (WWP; n = 5) and Casein vs 100\% Whey Partially

Hydrolyzed Protein (WPHP; $\mathrm{n}=6$ )

\begin{tabular}{lcccc}
\hline & Casein $(\mathrm{n}=5)$ & $50 \% \mathrm{WWP}$ & Casein $(\mathrm{n}=6)$ & $100 \% \mathrm{WPHP}$ \\
\hline Total reflux episodes & $55(24.5-194.5)$ & $32(17.5-194)$ & $41.5(9-87.5)$ & $25.5(14.3-68.3)$ \\
Acid episodes & $1(0-26.5)$ & $0(0-36)$ & $1(0-9.5)$ & $2(0-8.5)$ \\
Nonacid episodes & $39(24-176)$ & $32(13-162)$ & $23.5(8.3-87.3)$ & $14.5(12-68)$ \\
Reflux pH index & $0.5(0-1.9)$ & $0(0-5.9)$ & $0(0-1.7)$ & $0.7(0-2.6)$ \\
\hline
\end{tabular}

the whey formulas produced a similar acceleration in GE compared to the casein formula (Table 3). Five of the 13 patients (39\%) who had delayed GE with the casein-based formula normalized with 1 of the whey formulas (using the age-related reference range ${ }^{20}$ ).

\section{Symptoms and Pain}

Median number of stools per day (recorded on the daily parent recording sheet) was unchanged between the casein vs whey formulas $(0.8$ [0.36-1.07] vs 0.86 [0.31-1.22], respectively), and there was also no difference in stool frequency between the 2 whey formulas. Individual symptoms of gagging, regurgitation, irritability, pain, or constipation (reported using the VAS) revealed no differences between scores for casein vs whey formulas. When the 5 individual symptoms (score out of 10 for each) were combined to produce an aggregate score (minimum score 0 , maximum score 50 for each patient), again there was no difference between scores for casein vs whey formulas $(4.5[0-8.6]$ vs 3 [0-17], respectively). However, when comparing the 2 whey formulas, although there was no difference during the casein week, aggregate scores for reported symptoms were significantly lower in children who received the $50 \%$ WWP vs $100 \%$ WPHP (Table 3). There was no correlation between the acceleration in GE and reduction in symptoms in the 50\% WWP group $(r=0.49, P=.356)$.

Reports of pain (using the 3 assessment methods) were combined to produce an aggregate median score, which revealed that the overall level of pain was not different from the casein to the whey week (8.7 [1.2-17.9] vs 11 [2.5-32.7], respectively). However, when comparing the 2 whey formulas, although there was no difference during the casein week, aggregate scores for reported pain were significantly lower in children who received the 50\% WWP vs those who received $100 \%$ WPHP, whose pain scores worsened (Table 3).

\section{Discussion}

This study investigated the effect of a casein- vs wheybased enteral formula on GOR, GE, and symptoms in children who have severe $\mathrm{CP}$ with a gastrostomy and 
Table 3. Median (Interquartile Range) Scores for GE $\mathrm{t}_{1 / 2}$ (minutes), Aggregate VAS Symptoms, and Aggregate Pain Scores for the Casein Formula and 2 Whey Formulas

\begin{tabular}{lcccc}
\hline & Casein $(\mathrm{n}=7)$ & $50 \%$ WWP & Casein $(\mathrm{n}=6)$ & $100 \%$ WPHP \\
\hline GE t $_{1 / 2}$, min & $56.6(56-394.9)$ & $33.1(27.5-187.1)$ & $59.5(24-86)$ & $39(22.5-90.6)$ \\
Aggregate VAS symptoms score & $4.7(0-9.2)$ & $0(0-11.8)^{*}$ & $3.5(0-13.0)$ & $13.0(2.5-24.8)^{*}$ \\
Aggregate pain score & $6.4(0-19.6)$ & $3.0(2.0-11.0)^{* *}$ & $9.1(1.3-23.5)$ & $32.7(11.8-43.4)^{* *}$ \\
\hline
\end{tabular}

Those on 50\% WWP had significantly lower reported symptoms score $\left({ }^{*} P=.035\right)$ and lower pain score $\left({ }^{*} P=.014\right)$ compared to those on $100 \%$ WPHP. GE, gastric emptying; VAS, visual analog scale; WPHP, whey partially hydrolyzed protein; WWP, whey whole protein.

fundoplication. We observed that the whey-based formula (compared to casein) accelerated GE, but this improvement in GE did not alter GOR frequency or GI symptoms.

Few studies have examined the GI function of CP children, especially with respect to nutrition manipulation of the enteral formula. Those that have vary significantly in the quality of the experimental design. Criticisms of previous study designs include lack of randomization, blinding, control for positioning of the child, control for nutrition status, ${ }^{22}$ and control for variables in the formula constitution, including protein, lipid, and carbohydrate concentrations; osmolality; and caloric density. We aimed to minimize as many variables as possible (with what was commercially available), with our formulas only differing in the amount of whey, protein fractionation, and type of fat. As we were unable to commercially source a predominantly whey-based formula (whole protein), we studied 2 whey formulas with 50\% WWP and 100\% WPHP (Table 1).

Our study is the first to investigate $\mathrm{pH}$ impedancemeasured GOR in CP children. Standard $\mathrm{pH}$ probes, which are still common practice, have significant limitations $^{23-25}$ as it is likely that much of the refluxate is missed because of frequent milk-based enteral feeding, which buffers gastric $\mathrm{pH}$. Using $\mathrm{pH}$ impedance, we found that indeed most of the reflux episodes in these children were nonacid. However, we found no effect of whey vs casein in reducing acid, nonacid, total reflux episodes, and $\mathrm{pH}$ index. It must be noted, however, that because of an increase in fundoplication surgery performed together with gastrostomy, ${ }^{26}$ all but 1 child had undergone fundoplication. We predict this would have markedly reduced the amount of overall reflux in the cohort, making it difficult to demonstrate further reductions in GOR in relation to a feeding intervention. It is therefore not surprising that our findings contrast with the study of Khoshoo et al, ${ }^{14}$ who studied CP children with GOR symptoms but without fundoplication and showed a significant reduction in acid GOR episodes (by pH-metry) with a whey-based enteral formula $(P<.05)$.
In relation to GE and whey-based formulas, the small amount of research is suggestive of whey formulas accelerating GE in children with CP. ${ }^{13}$ GE of 3 whey-based formulas (compared to casein) was studied in $9 \mathrm{CP}$ children with GOR. A significant acceleration in GE was found with all whey formulas compared to casein $(P<$ $.001) .{ }^{13}$ Despite the 3 whey formulas varying in amount of whey protein, protein concentration, protein fractionation, presence of LCT vs MCT, caloric density, and osmolality, they showed no significant difference between them in their effect on GE. Similarly, a pilot study of 15 enterally fed children with CP showed a significant acceleration in mean GE $\mathrm{t}_{1 / 2}$ (measured by ${ }^{13} \mathrm{C}$-Na-octanoate breath test) with a $60 \%$ whey formula compared to a casein-based formula $(P<.001) .{ }^{12}$

Although we found a significant improvement in GE with the whey formula, whether or not this translates into improved enteral feed tolerance is an important question. We found no difference in GI symptoms between casein vs whey, but we found a significant difference between the 2 whey formulas, with the children consuming the $50 \%$ WWP experiencing less symptoms than those consuming the $100 \%$ WPHP. Graham-Parker, ${ }^{27}$ who studied children with severe CP (aged 2-9 years), found that children consuming a $50 \%$ whey formula had significantly less reported gagging and retching (but not vomiting) compared to those consuming a casein-based formula $(P$ $<.001)$.

We found no correlation between the acceleration in GE and improvement in pain or symptoms in the $50 \%$ WWP group and in fact a worsening of these scores in the $100 \%$ WPHP group (despite accelerated GE). It is not known whether this is a function of small sample size or whether another factor is influencing GI symptoms. Why the $100 \%$ WPHP group in our study experienced significantly greater pain and symptoms scores compared to the $50 \%$ WWP is unclear. It could be hypothesized that the higher MCT content of the 100\% WPHP formula (compared to 50\% WWP or casein), which was the biggest variable between all formulas, may possibly contribute to the increased symptoms in this population. The daily dosage 
of MCT that is well tolerated by individuals is not well documented, and there are conflicting data regarding the tolerable doses that avoid GI upset. ${ }^{28,29}$

In conclusion, our pilot study shows that in children who have severe $\mathrm{CP}$ with a gastrostomy and fundoplication, GE of whey-based enteral formulas is significantly faster than casein-based formulas. A 50\% whey whole-protein formula is better tolerated with less GI symptoms and pain than a $100 \%$ whey partially hydrolyzed formula. The acceleration in GE does not alter GOR frequency and does not correlate with symptomatic improvement. Our results indicate that enteral formula selection may be particularly important for children with severe CP and delayed GE.

\section{References}

1. Schemann M. Control of gastrointestinal motility by the 'gut brain'-the enteric nervous system. J Pediatr Gastroenterol Nutr. 2005;41:S4-S6.

2. Sullivan PB. Gastrointestinal disorders in children with neurodevelopmental disabilities. Dev Disabil Res Rev. 2008;14:128-136.

3. Wood JD, Alpers PH, Andrews PL. Fundamentals of neurogastroenterology. Gut. 1999;45:11-16.

4. Ravelli AM, Milla PJ. Vomiting and gastroesophageal motor activity in children with disorders of the central nervous system. J Pediatr Gastroenterol Nutr. 1998;26:56-63.

5. Del Guidice ED, Staiano A, Capano G, et al. Gastrointestinal manifestations in children with cerebral palsy. Brain Dev. 1999;21:307-311.

6. Sondheimer JM, Morris BA. Gastroesophageal reflux among severely retarded children. J Pediatr. 1979;94(5):710-714.

7. Di Lorenzo CD, Benninga MA, Forbes D, et al. Functional gastrointestinal disorders, gastoesophageal reflux and neurogastroenterology: working group report of the Second World Congress of Pediatric Gastroenterology, Hepatology and Nutrition. J Pediatr Gastroenterol Nutr. 2004;39:S616-S625.

8. Durante A, Schettini S, Fagundes D. Vertical gastric plication versus Nissen fundoplication in the treatment of gastroesophageal reflux in children with cerebral palsy. Sao Paulo Med J. 2007;125(1):15-21.

9. Wales PW, Diamond IR, Dutta S, et al. Connolly B, Langer JC. Fundoplication and gastrostomy versus image-guided gastrojejunal tube for enteral feeding in neurologically impaired children with gastroesophageal reflux. J Pediatr Surg. 2002;37:407-412.

10. Vandenplas Y. Diagnosis and treatment of gastroesophageal reflux disease in infants and children. J Gastroenterol Hepatol. 2000;15(6):593-603.

11. Miele E, Staiano A, Tozzi A, Auricchio R, Paparo F, Troncone R. Clinical response to amino acid-based formula in neurologically impaired children with refractory esophagitis. J Pediatr Gastroenterol Nutr. 2002;35:314-319.

12. Brun AC, Medhus AW, Johannesdottir GB, et al. Effect of protein composition on gastric emptying rate in children with cerebral palsy. 2008. http://manage.nutricia.com/uploads/documents/ Small_Talk_winter2008v21.pdf. Accessed September 29, 2011.

13. Fried MD, Khoshoo V, Secker DJ, Gilday DL, Ash JM, Pencharz PB. Decrease in gastric emptying time and episodes of regurgitation in children with spastic quadriplegia fed a whey-based formula. J Pediatr. 1992;120(4, pt 1):569-572.

14. Khoshoo V, Zembo M, King A, Dhar M, Reifen R, Pencharz P. Incidence of gastroesophageal reflux with whey- and casein-based formulas in infants and in children with severe neurological impairment. J Pediatr Gastroenterol Nutr. 1996;22:48-55.

15. Mahe S, Roos N, Benamouzig R, et al. Gastrojejunal kinetics and the digestion of $\left[{ }^{15} \mathrm{~N}\right] \beta$-lactoglobulin and casein in humans: the influence of the nature and quantity of the protein. Am J Clin Nutr. 1996;63:546-552.

16. Stevenson RD. Use of segmental measures to estimate stature in children with cerebral palsy. Arch Paediatr Adolesc Med. 1995; 149:656-662.

17. Lewis D, Khoshoo V, Pencharz PB, Golladay ES. Impact of nutritional rehabilitation on gastroesophageal reflux in neurologically impaired children. J Pediatr Surg. 1994;29(2):167-170.

18. Woods SDS, Mitchell GJ. Delayed return of gastric empting after gastroenterostomy. Br J Surg. 1989;76:145-148.

19. Barnett C, Snel A, Omari T, Davidson G, Haslam R, Butler R. Reproducibility of the ${ }^{13} \mathrm{C}$-octanoic acid breath test for assessment of gastric emptying in healthy preterm infants. J Paediatr Gastroenterol Nutr. 1999;29(1):26-30.

20. Van Den Driessche M. Study of Gastrointestinal Motility in Infants and Children Using 13C Breath Tests [dissertation]. Leuven, Belgium: Leuven University; 2001.

21. Breau L, McGrath P, Camfield C, Finley G. Psychometric properties of the Non-communicating Children's Pain Checklist-Revised. Pain. 2002;99:349-357.

22. Woodley F, Mousa H. Revisiting the effect of casein and whey on gastric emptying: do differences in protein source really matter? $J$ Neonatal Perinatal Med. 2008;1:111-117.

23. Del Buono R, Wenzl T, Rawat D, Thomson M. Acid and nonacid gastro-oesophageal reflux in neurologically impaired children: investigation with the multiple intraluminal impedance procedure. J Paediatr Gastroenterol Nutr. 2006;23(3):331-335.

24. Omari T. Gastro-oesophageal reflux disease in infants and children: new insights, developments and old chestnuts. J Pediatr Gastroenterol Nutr. 2005;41:S21-S23.

25. Sifrim D, Castell D, Dent J, Kahrilas PJ. Gastro-oesophageal reflux monitoring: review and consensus report on detection and definitions of acid, non-acid and gas reflux. Gut. 2004;53:1024-1031.

26. Vernon-Roberts A, Sullivan P. Fundoplication versus post-operative medication for gastro-oesophageal reflux in children with neurological impairment undergoing gastrostomy. Cochrane Database Syst Rev. 2007;(1):CD006151.

27. Graham-Parker C. Effect of whey-based diet on incidence of vomiting in G-tube fed children with severe neurodevelopmental delay. JPEN J Parenter Enteral Nutr. 2001;25:S14.

28. Bach A, Babayan V. Medium chain triglycerides: an update. Am J Clin Nutr. 1982;35:950-962.

29. Jeukendrup A, Saris W, Wagenmakers J. Fat metabolism during exercise: a review. Int J Sports Med. 1998;19:371-379. 